\title{
BMJ Open The social cure of social prescribing: a mixed-methods study on the benefits of social connectedness on quality and effectiveness of care provision
}

\author{
Blerina Kellezi (1) , Juliet Ruth Helen Wakefield (1) , Clifford Stevenson (1) , \\ Niamh McNamara (D), Elizabeth Mair (D), Mhairi Bowe (D), lain Wilson (D), \\ Moon Moon Halder (D)
}

To cite: Kellezi B,

Wakefield JRH, Stevenson C, et al. The social cure of social prescribing: a mixedmethods study on the benefits of social connectedness on quality and effectiveness of care provision. BMJ Open 2019;9:e033137. doi:10.1136/ bmjopen-2019-033137

- Prepublication history for this paper is available online. To view these files, please visit the journal online (http://dx.doi org/10.1136/bmjopen-2019033137).

Received 22 July 2019 Revised 20 September 2019 Accepted 18 0ctober 2019

Check for updates

(C) Author(s) (or their employer(s)) 2019. Re-use permitted under CC BY-NC. No commercial re-use. See rights and permissions. Published by BMJ.

Psychology, Nottingham Trent University, Nottingham, UK

Correspondence to Dr Blerina Kellezi, Department of Psychology, Nottingham Trent University, Nottingham, United Kingdom;

blerina.kellezi@ntu.ac.uk

\section{ABSTRACT}

Objectives This study aimed to assess the degree to which the 'social cure' model of psychosocial health captures the understandings and experiences of healthcare staff and patients in a social prescribing (SP) pathway and the degree to which these psychosocial processes predict the effect of the pathway on healthcare usage.

Design Mixed-methods: Study 1: semistructured interviews; study 2: longitudinal survey.

Setting An English SP pathway delivered between 2017 and 2019.

Participants Study 1: general practitioners (GPs) $(n=7)$, healthcare providers $(n=9)$ and service users $(n=19)$. Study 2: 630 patients engaging with SP pathway at a 4-month follow-up after initial referral assessment.

Intervention Chronically ill patients experiencing loneliness referred onto SP pathway and meeting with a health coach and/or link worker, with possible further referral to existing or newly created relevant third-sector groups.

Main outcome measure Study 1: health providers and users' qualitative perspectives on the experience of the pathway and social determinants of health. Study 2 : patients' primary care usage.

Results Healthcare providers recognised the importance of social factors in determining patient well-being, and reason for presentation at primary care. They viewed SP as a potentially effective solution to such problems. Patients valued the different social relationships they created through the SP pathway, including those with link workers, groups and community. Group memberships quantitatively predicted primary care usage, and this was mediated by increases in community belonging and reduced loneliness. Conclusions Methodological triangulation offers robust conclusions that 'social cure' processes explain the efficacy of SP, which can reduce primary care usage through increasing social connectedness (group membership and community belonging) and reducing Ioneliness. Recommendations for integrating social cure processes into SP initiatives are discussed.

\section{INTRODUCTION}

\section{The burden of loneliness}

Ageing populations and increasing demand for health services are just two of the challenges
Strengths and limitations of this study

- It identifies mechanisms that underlie effective social prescribing (SP) interventions.

- It identifies mechanisms that enable more appropriate use of primary care services.

- It reports the most comprehensive multiperspective evaluation of a National Health Service model of SP to date, with accounts from general practitioners, link workers, health coaches and patients.

- The results observed in our longitudinal analysis are short term and are likely to develop further over longer time periods, although observing benefits after such a short time is promising.

- The specific characteristics of this sample (adults with complex health needs from across the socioeconomic spectrum, living in a relatively affluent area) need to be borne in mind when considering the applicability of SP to other populations.

currently facing the UK's National Health Service (NHS), all of which impede medical professionals' ability to provide high-quality healthcare. ${ }^{12}$ These challenges are exacerbated by increasing loneliness experiences (eg, HoltLunstad $e t a l^{3}$ ). Loneliness has been linked to reductions in perceived physical health ${ }^{4}$ and cognitive health, ${ }^{5}$ and increased risk of multimorbidity, ${ }^{6}$ difficulties performing daily tasks, ${ }^{7}$ depression $^{8}$ and mortality. ${ }^{9}$

Loneliness has also been linked to increased contact with primary care services especially among the elderly, ${ }^{11}{ }^{11}$ with loneliness ${ }^{12}$ and associated mental-health concerns ${ }^{13}$ being increasingly common reasons for general practitioner (GP) visits. Multinational surveys, including the UK, show that around onethird of patients with depression/anxiety contact primary care, ${ }^{14}$ but fewer than onethird of these receive treatment. ${ }^{15}$ Thus, there is an urgent need to adopt more patientcentred holistic care provision that considers 
Table 1 Participant characteristics

\begin{tabular}{ll}
\hline Characteristic & Patients \\
\hline N & 19 \\
Age & $29-85$ years (average age: 60.4 years)
\end{tabular}

GPs LWs/HCs

\section{7}

33-53 years; three unknown (average age 43 years)

\section{$3 \mathrm{HCs}$ and $6 \mathrm{LWs}$}

HC: $47-50$ years (average age 48.43 years). LW: 22-52 years, 1 unknown (average age 30.80 years)

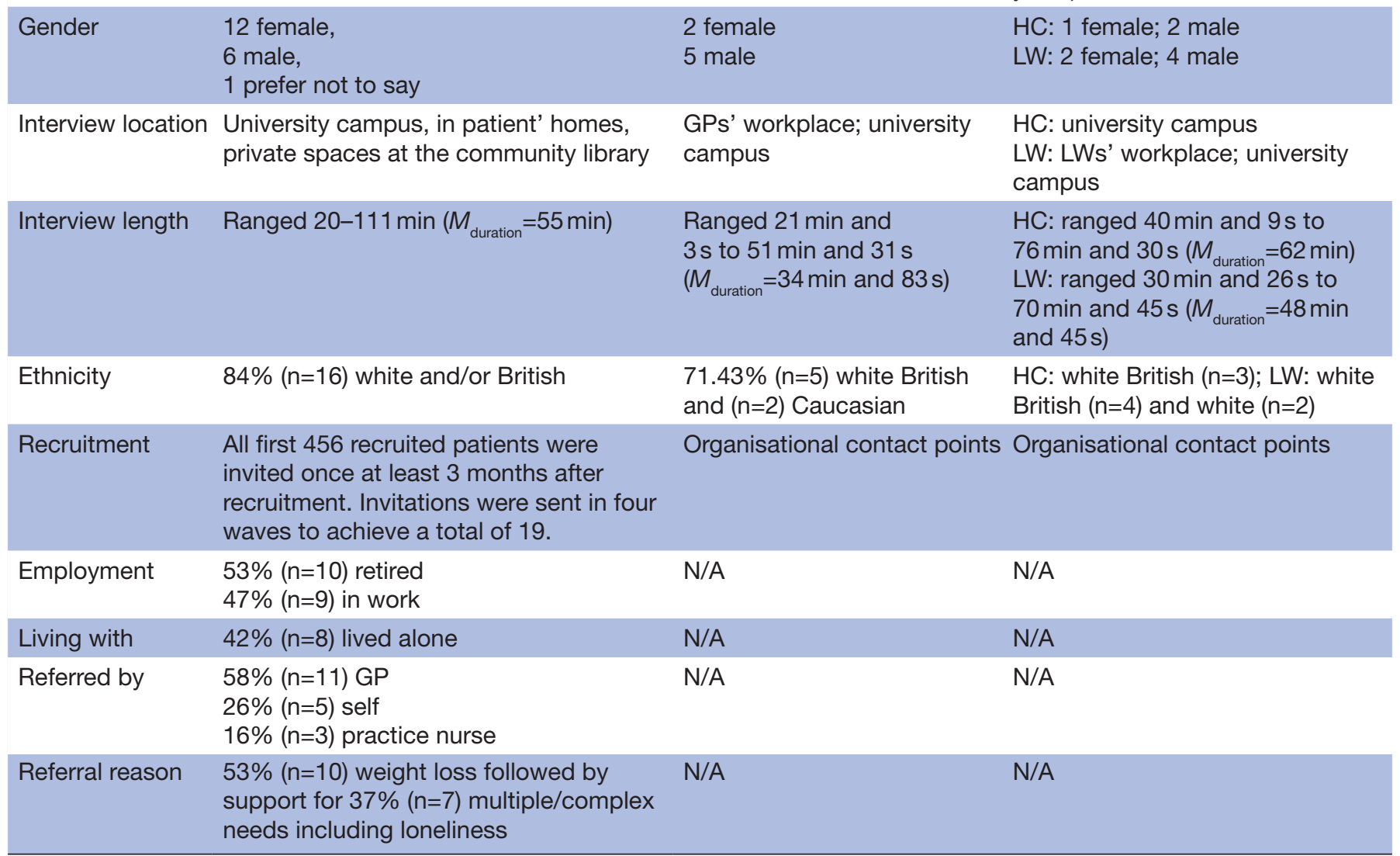

GP, general practitioner; HC, health coach; LW, link worker.

psychosocial factors alongside physical health needs. ${ }^{16-18}$ Any meaningful plan to address these challenges must therefore consider the issue of loneliness and physical/ mental health. ${ }^{19-21}$

An additional challenge is the need to engage primary care services in the recognition and treatment of psychosocial needs (eg, loneliness). Although GPs are the primary point of contact, ${ }^{22}$ they struggle to address mental health/loneliness for several reasons: limitations in psychological training ${ }^{23}$; the additional length of time required for discussing mental health compared with physical health ${ }^{24}$; and limited mental-health referral options. ${ }^{25} \mathrm{~A}$ key challenge is therefore to provide a clear and evidence-based approach to understanding and identifying the effects of loneliness, as well as the services necessary to alleviate this healthcare burden.

\section{Social prescribing as a cure for loneliness}

Healthcare commissioners/providers have recently begun implementing novel initiatives that could reduce the economic burden of loneliness. One such initiative is social prescribing $\left(\mathrm{SP}^{26}\right)$, which represents a departure from traditional medical models of healthcare. Rather than focussing on medication provision, SP involves addressing patients' needs holistically. GPs initially profile potential patients, especially those suffering from chronic conditions exacerbated by loneliness (eg, depression, obesity). In some SP pathways, health coaches (HCs) receive these referrals and provide patients with practical and emotional support, as well as opportunities to better manage their own health. The 'social' aspect comes from SP's links to the community: patients are supported to join third-sector groups (eg, voluntary, social enterprise) to enhance social connection and reduce loneliness. Patients are supported by link workers (LWs), who connect them to relevant groups and support their attendance. Ultimately, SP is designed to improve well-being and illness self-management while addressing social needs and reducing primary health-service usage.

Although there has been a proliferation of different models of SP, each conceptualising and addressing loneliness differently, there is growing evidence regarding their general efficacy. SP initiatives have been shown to enhance 
service-users' well-being, quality of life, patient activation, health-related confidence, community involvement and experience of services, ${ }^{27-29}$ as well as to reduce anxiety, emotional problems, loneliness and healthcare use. ${ }^{30-32}$ Provision of group activities is also a highly effective way to address loneliness ${ }^{33} 34$ and improve health. ${ }^{35}$ Economic return on investment has also been evidenced, ${ }^{28}{ }^{36-38}$ with some reports showing better return from services delivered by voluntary/community organisations. ${ }^{37}$ These positive outcomes have led to an increase in GPs advocating for $\mathrm{SP}^{39}$

While this suggests that SP holds a great deal of potential, a major limitation of the existing evaluated interventions is that they lack an underpinning theoretical framework. ${ }^{40}$ This impedes the identification of SP's 'active ingredients', and the specific processes through which initiatives can alleviate loneliness, improve heath and reduce healthcare burdens. Specifically, the proliferation of different SP models has created confusion as to how to understand loneliness, operationalise its treatment and measure its outcomes. ${ }^{41}$ This means the profiling of potential patients, the identification of their needs and the delivery of treatment can be ad hoc and piecemeal. Furthermore, lack of clarity among those referring/treating patients, as well as between staff and patients, fosters poor levels of uptake, engagement and treatment. ${ }^{42} 43$ A clearer theoretical understanding of the relationships between loneliness, health and treatment is needed, and from this, greater consistency in the messages delivered regarding SP.

\section{The 'social cure' as a theoretical framework for SP}

The pathway evaluation reported here is underpinned by an appropriate psychosocial framework: the social identity approach to health and well-being, aptly named 'The Social Cure' $\left(\mathrm{SC}^{44}{ }^{45}\right)$. This approach posits that our social group memberships (eg, family, community, volunteering group) are consequential for our social life, health and well-being, but only if we identify with them (ie, feel a subjective sense of group belonging ${ }^{46}$ ). Group identification is believed to enhance social life and well-being through numerous benefits, such as reduced loneliness, enhanced self-esteem and the belief that social support will be available during crisis (eg, Greenaway et al and Haslam et $a l^{4748}$ ).

\section{Case study: SC in action in an SP pathway}

This study is part of a larger programme of research which uses a multimethod, longitudinal approach to explore these social processes in the context of an ongoing SP pathway (see protocol for details ${ }^{49}$ ). Our research has two aims. First, we determine which social factors are central to the understanding of SP and how SP is experienced among: (1) GPs currently referring to this SP pathway; (2) HCs/LWs delivering the pathway; (3) patients participating in the pathway. From this, we aim to provide an evidence base for the relevance and explanatory power of the SC framework in capturing the 'active ingredients' in SP delivery. Second, using a longitudinal survey, we seek to provide evidence for whether the SP pathway does have its effects through these
SC processes, and the consequences of this for patients' health-service use. We now briefly summarise the key details of the specific SP pathway.

\section{Overview of the SP pathway}

The SP pathway began in the English East Midlands in 2017. The pathway is supplemental to any healthcare the patient is already receiving and is designed for patients with chronic illness who are experiencing loneliness. The GP practices in the area covered a population of over 120000 people. They were introduced and encouraged to participate in the pathway by designated SP advocate GPs, but the level of referrals varied across the practices. The aims are to increase patients' illness self-management, address their psychosocial and health needs, and through this to reduce primary healthcare usage. Once recruited onto the pathway, patients have an initial meeting and needs assessment with an HC, who either prescribes self-care management or refers to an LW, who in turn connects the patient with relevant third-sector groups. HC/LWs regularly check on patients' progress. The aim of the pathway was to support each patient weekly for up to 8 weeks. The length of support depended on the specific paths offered. By the follow-up assessment, some participants received this number of one-to-one support meetings, while others had fewer meetings with HC and LW as they had joined group activities and thereafter met with their groups. By the end of the funding, the pathway had received 1483 referrals and supported approximately 650 patients. The initial appointment lasted over 1 hour, and further appointments ranged in length based on the activities in which the patients were involved.

\section{STUDY 1}

Study 1's aim was to gain a deeper insight into perceptions/understandings of the social factors influencing health and presentation to primary care. Specifically, we intended to investigate the degree to which referrers (GPs), those delivering the pathway (HCs/LWs) and patients themselves recognise experiences of social (dis) connection, and appreciate the effects of these experiences, as well as SP's potential to remedy these issues.

\section{METHOD}

\section{Participants and procedure}

In-depth, semistructured interviews were conducted with 7 GPs (referring into the pathway), 3 HCs, 6 LWs (involved in pathway delivery) and 19 patients (full characteristics and recruitment details can be found in table 1 ).

All potential participants were invited through their managers (email invitation letters were sent to all participating GPs, HCs and LWs) or pathway staff (letters were sent to the first 80 patients recruited onto the pathway, and then the next 200 patients, due to a low response rate). All those interested were invited to contact the researcher via email/phone/post for further information 
and to arrange a time for the interview. Further details can be found in the published protocol. ${ }^{49}$ The interviews included a range of general topics: participants' understanding of SP; their experience of the pathway; the process of referrals through the pathway; and perceptions of the pathway's success (or otherwise). There were also role-specific questions, such as the needs of patients (GPs); experiences of facilitating patient support/ engagement (HCs); and involvement with the groups to which they had been linked (patients).

The analysis was separated for each group of participants. This paper focuses on data sections where participants reflect on relationships between psychosocial needs and service use, and the need for/value of SP, guided by the social cure framework. All interviews were audiorecorded, transcribed verbatim and analysed with a realist approach using the six thematic analysis steps. ${ }^{50} 51$ The purpose was to provide a detailed account of participants' views with regard to the specific research questions, using a deductive approach. Two authors conducted the interviews, then data familiarisation began through repeated listening to interviews, transcript reading and notetaking. Two authors completed initial coding, which was inclusive: the whole corpus was coded, and the resultant list of codes was collated. Three authors then discussed the relationships between codes and considered how they fitted into potential themes/subthemes. Candidate themes were reviewed to ensure the presence of meaningful/coherent data within themes, and distinctiveness across themes. Finally, themes were defined, named and reported. Quotes illustrate the analyses, completed with participant number, indicating omitted lines with (...).

\section{Patient and public involvement}

Patients and the public were not involved in the design, analysis and dissemination of this research.

\section{RESULTS}

\section{GP perspective: social factors and the need for a holistic service}

GPs recognised that a change is required in terms of how health, well-being and social concerns are understood/ addressed by health services and society. They described how the NHS traditionally does not address social isolation. Achieving this would require a broader approach addressing mental, physical and social health:

Traditionally as well this used to be very much an extended family village where most people related to each other (...) With the new families coming in they often don't know anybody, so they've lost that ability to support themselves. (...) So, we have many isolated people in the village, lots of single people who, you know, have become lonely and worried about their health just because they've got all the time in the world to sit and think about it. (...) So to have a more sustainable programme I think it will be excellent,
I can see it growing, just because of the number of people with diabetes for instance who need encouragement, it's going through the roof, you know, we can't keep pace with them all and we certainly individually cannot fund the education programmes that are needed, so it needs to be done in a CCG wide fashion. (GP 4)

This GP describes how GPs are overwhelmed and cannot provide support for social determinants of health such as social isolation, leading to patients being overlooked. Alongside recognising the link between physical and social health determinants, GPs perceived a shift from a traditional medical model towards recognising the need to provide support for lonely patients:

Well, most of a population's health and well-being is determined by environmental factors, and things that are not to do with healthcare. And, you know, sometimes the traditional medical model (...), our role is to just do the medicine and that's it. But we work in a system. (...) All these things are interdependent, and if we want to, we might not be the experts on it, but if we want to help our patients more and help the population, then we need to access these sort of broader things. (GP 5)

There is recognition of the limitations of the 'traditional medical model', concerns over how GPs can support patients with different needs and frustration at the limitations within the current model. However, while GPs were perceived to be well-placed to identify those in need of healthcare, participant 5 recognised the limitations of GPs' own expertise in terms of addressing issues related to patients' social environments, and the need for a system that provides additional pathways necessary to address such issues. Across participants, SP was viewed as a means to support GPs in providing the best care for patients by addressing loneliness and reducing its negative health impacts:

People become more isolated and often present [at primary care services]. I had a lady who used to come and see me whose depression used to peak, and her mood deteriorated when her art classes stopped. Then, she used to come to the doctor a lot. When the art classes started up, we didn't see her. (GP 2)

By referring to frequent presentation, the participant highlights one of the challenges that primary care faces at a time of limited resources and increasing demand, while also reflecting on the cost this has to patients whose mental health is affected by isolation. Inherent in this account is a suggestion that community activities can alleviate mental health issues, as well as reduce primary care demands, which operates within a limited timeframe (average UK GP appointments last $9 \mathrm{~min}^{52}$ ). Experiences of isolation and a lack of social connection were thus recognised by GPs as a contributor to ill-health, as well 
as a key reason for accessing services. This recognition guided their SP pathway referrals.

GPs also discussed concerns about referring due to limited knowledge and understanding of the pathway and poor feedback on their referrals (all of which could influence the referrers' willingness to continue engaging with the pathway).

\section{LW/HC perspectives: social needs and community}

SP providers highlighted the importance of reconnecting patients with the community through SP initiatives. They articulated how SP can help combat loneliness/isolation through patients receiving social support from others undergoing the same experiences. It was also hoped that patients' increased knowledge of what is available in the community would improve their social confidence:

I think it is important, I think people can maybe lose their way a bit because of certain things that's happening in life and I think if, they can get locked away in their home, become isolated and anxious and I think if people know what's around them I think it might or it does help with getting them out, giving them a bit more motivation, talking to people in their area and understanding that it's not just them going through things their selves, you know, people are going through similar things. Yeah, so it's just something that they know they can go to, it might be a group that they know they can go to every week and feel comfortable with going to that. (LW 1)

Social support provision makes patients feel comforted, understood, motivated, less anxious and less isolated, but it can also involve patients sharing information about difficulties they are experiencing. SP providers argued that groups benefitted the whole community, as well as individual patients:

I think as we work with individuals to get them engaged more with the community, the community itself then benefits by having more people engaged with it, so it becomes almost organic and it can grow and develop itself, just to help to meet the needs of its members, I guess. (HC 5)

In this way, SP was understood to have the potential to make an impact in addressing social, physical and mental health concerns, and to develop a holistic health service. The success of the referrals and the pathway brought challenges for HCs/LWs who felt the increasing numbers could impact the quality of services provided.

\section{Patients' perspective: relationship with LW/HC and building social connections}

Relationship with LW/HC

Typically, patients described their interactions with pathway staff as positive. They liked having time to discuss challenges thoroughly and receiving tailored support. Patients felt that staff were empathetic to their needs, and they believed that SP was qualitatively different from their experiences with other health professionals:

I think when you go to the doctor, you're used to having this ten-minute slot and you have to like quickly get everything in. And then when you go and see a counsellor, or you go and see your support worker, you have that full hour, and I wasn't really used to that at the time, that expanse of time where you can just relax and talk. (Patient 3)

An important aspect of the support patients received was having someone listen to them. Patient 7 describes how she was supported in a way that allowed self-reflection on her challenges:

I felt as though they gave me the chance to reason out that I was getting better. I listened to them. I knew what was going on in my head, but I couldn't always, I didn't always want to tell anyone. I seemed, with the link-worker, I seemed as though I could get over that more quickly. He wasn't demanding. He was very quiet and very gentle with it, and that is the way that I needed somebody to be, to maybe listen to me, really listen to me, and hear what I was saying, if you can understand that. (Patient 7)

Patient 7 highlights an important aspect of the therapeutic relationship (which was echoed across accounts) when she notes that the LW 'wasn't demanding'. Participants saw this as a goal achievement facilitator. When discussing the progress of their goals with staff, beneficiaries experienced support as encouraging rather than punitive (contrary to their expectations). Two participants did not feel supported because the pathway staff failed to maintain contact as expected, or interacted in what was perceived as a rushed manner. This in turn made the patients feel their needs were not understood.

\section{Building social connections}

For patients who were socially isolated and coping with complex health issues, joining community groups was challenging. Some expressed fear of going outside the home, or anxiety about meeting new people. LW support was vital for becoming more socially connected, specifically being accompanied by the LW to the first group meeting:

[The LW] said that both of us could go to [the group] the first time, so that she could help me make sure I was comfortable and that I had what I needed to do the class. She spoke to [the instructor] and introduced me to her. I felt a lot happier knowing I had someone I knew to go with me. [lines omitted] If someone had just told me to go, I don't think I would have gone. (Patient 8)

Many patients described increased feelings of selfconfidence following their pathway participation. This was particularly evident for those with complex conditions and/or social isolation. Some credited LW support 
as facilitating self-confidence improvements and their ability to make new connections.

A positive group experience was also vital. This was typically facilitated by a sense of belonging and feeling welcomed by the group (and leader). Aside from loneliness alleviation, groups allowed participant 4 to provide support to similar others, which he experienced as an important aspect of group membership:

You're kind of helping each other, because I think for most people [with this condition] you kind of feel that you're the only person on the whole of Plant Earth, you know. You don't seem to know how many other people [have this condition] so the fact that you can meet up with others is like, oh, there are other people that understand and know how it's difficult (...) and so, you were able to give each other encouragement or copy each other or learn from each other. (Patient 4)

Thus, for patients, positive relationships with LWs and group members were essential prerequisites for engaging in social activities and connecting with others, thus addressing social isolation/loneliness.

Sustaining meaningful connections with groups aided confidence building. For example, participant 3 explained how she was now confident enough to attend sessions on her own, as well as join further groups (and return to groups she had previously left due to health issues), thus building further connections:

So, I didn't know there were people out there like me, and $[\mathrm{LW}]$ made me realise (...), there are lots of people out there like me and we're like a little tribe. And there's little places we can go and hook up and just kind of like talk about anything you want, or not talk at all. And I just think it saved me. Honestly, I don't know what would have happened. It terrifies me to think what would have happened. I think I would have got more ill, if I'm honest, because I was desperate. (Patient 3)

The positive benefits of group engagement were thus enabled by the LW, who served as connector and confidence builder. Typically, participants did not feel positive about the SP pathway when they felt the groups they were referred to did not meet their needs or they felt unwelcomed. Participant 8 , who had a negative group experience, suggested that $\mathrm{SP}$ groups should be sensitive to the issues that patients who joined the group might be dealing with:

Whoever's running a particular class should be made aware of the programme itself and the issues and the impact it could have on the people who have eventually managed to get out of the house, and treat them a little better.

In this case, the participants highlight their disappointment in not feeling well treated or having their needs understood, especially after a lot of effort was required to make the first step ('leave the house'). Thus, rather than fostering connection, group participation seems to add to the issues rather than address them.

\section{DISCUSSION}

Our analysis reveals that these GPs recognise the limits of the medical model in addressing patient well-being, especially those with complex chronic conditions. All participants recognised the potential role of SP in addressing social needs and the unique role that LWs, groups and communities can play in establishing these benefits. Importantly, the analysis also confirms that patients recognise how social factors affect their health, and reports how social connectedness/belonging benefits their health.

This is preliminary evidence for the relevance of the SC perspective for the understanding of SP. Both providers and patients report the negative effects of social isolation on health/healthcare usage, as well as the positive benefits of social inclusion/belonging. Moreover, SP providers and patients specify that it is the quality of the social relations which has well-being benefits. In particular, patients report various factors, including feelings of acceptance and belonging within activity groups/communities, which are central to understanding the health benefits of group memberships, as outlined in SC. Since reducing loneliness through building social connectedness (ie, group membership and community belonging) is central to both SP and SC, our second study determines whether these factors do indeed impact on loneliness and healthcare usage (another core aim of SP).

\section{STUDY 2}

\section{Aim}

Study 2 involved asking patients a survey of questions at the point of referral onto the SP pathway (T0) and at a subsequent time point (T1) to evaluate the overall efficacy of the pathway (for study protocol, see previous work $\left.^{49}\right)$. These data allow an analysis of the psychosocial factors mediating the relationships between change in group memberships and health service usage.

\section{Method}

\section{Predictions}

Based on SC, we hypothesise that possessing group memberships will positively predict a psychological sense of community belonging, which in turn will be associated with lower levels of loneliness. In turn, we propose that this serial mediation pathway will then predict service usage which, if supported, would constitute a particularly strict test of our SC model. Based on previous SP literature and the social identity approach, the two variables we expected to change during the pathway were patients' service use (decrease) and participants' number of group memberships (increase). While we did not necessarily expect the other variables (eg, community belonging, loneliness) to change during the short period between $\mathrm{T} 0$ and $\mathrm{T} 1$, we expected these (based on SC theorising) 
to be the 'active ingredients' through which an increase in participants' number of group memberships would predict reductions in service use.

\section{Participants and procedure}

All data were gathered during the first 18 months of pathway operation (November 2017-February 2019). (In the published protocol, ${ }^{49}$ it is specified that there will be additional follow-ups, but due to delays in setting up the intervention and higher levels of referral than expected, there was no funding available to complete the additional planned follow-ups.) T0 survey data $(n=630)$ were gathered by HCs delivering the survey face-to-face in the first meeting at participants' GP surgeries (285 male, 340 female, 5 unknown; $M_{\text {age }}=52.74$ years, $\left.S D=14.79\right)$. T1 data were collected via phone/face-to-face on average 4 months after T0, during a routine follow-up with HCs for 178 participants (86 male, 91 female, 1 unknown; $M_{a g e}=55.75$ years, $S D=13.80$ ). Using $G^{*}$ Power, ${ }^{53}$ we computed an a priori minimum sample size of 49 for a repeated measures analysis of variance (ANOVA), assuming a partial $\eta 2$ of 0.147 (the value we obtained in the service use repeated measures ANOVA described in the Results section) and 0.80 power. Bonferroni-corrected between-group t-tests revealed that $\mathrm{T} 1$ responders had significantly more group memberships $(M=1.89, S D=1.59)$ than $\mathrm{T} 1$ non-responders $(M=1.51, S D=1.37), \quad t(628)=-2.94, \mathrm{p}=0.003$, and were significantly older $(M=55.75, S D=13.80)$ than nonresponders $(M=51.56, S D=15.01), t(625)=-3.22, \mathrm{p}=0.001$. All other $\mathrm{p}$ values were $>0.05$.

\section{Survey measures}

Patients were given a list of 10 social groups ("family; sports clubs, gyms or exercise class; tenant group/resident group/neighbourhood watch; political party/trade union/environmental group; church or other religious group; education/art/music group, or evening class; social club; support group (eg, diabetes support); any other organisations, club or society') and were asked to indicate to which they belong to. Alternatively, patients could tick ' $I$ am not a member of any groups'. From this, patients' number of group memberships (0-10) was calculated.

We measured community belonging with a single item previously used in population surveys of social attitudes ${ }^{54}$ ('Thinking about this local community, the kind of place it is and the kind of people who live around here, would you say that you feel a sense of belonging to this local community?). Patients rated their agreement on a 1 (definitely not) to 4 (yes definitely) scale.

We measured loneliness with the eight-item UCLA Loneliness Scale (ULS-8) ${ }^{55}$ Patients rated their agreement with each item (eg, 'I lack companionship') on a 1 (not at all) to 5 (completely) scale. The mean score of the items was found, with higher values indicating greater loneliness.

Health service use was measured by asking patients to indicate the number of times they have used primary care (eg, GP in-person appointments, GP phone appointments) in the previous 3 months, using an adapted measure from Kellezi $e t a l^{56}$ Change in service usage was also calculated since service use reduction is a core goal of SP.
Finally, patients were asked to specify their age, gender, whether they were in a relationship and their highest level of education.

\section{Statistical analyses}

We conducted a repeated-measures ANOVA to compare $\mathrm{T} 0 / \mathrm{T} 1$ service use and $\mathrm{T} 0 / \mathrm{T} 1$ number of group memberships. Additionally, we used model six in V.3.0 of PROCESS macro ${ }^{57}$ to test our SC-derived prediction that possessing more group memberships at $\mathrm{T} 1$ than $\mathrm{T} 0$ will predict higher community belonging, which in turn will predict lower loneliness, which in turn will predict less primary care usage. The analyses involved 5000 bootstrapping samples with $95 \%$ CI (Lower Level For Confidence Interval (LLCI)/Upper Level For Confidence Interval (ULCI)) using the percentile method. Values were mean centred for the construction of products. Participants' gender, age, relationship status, employment status and highest level of education were controlled for, as were the $\mathrm{T} 0$ versions of the mediator and predictor variables (ie, community belonging, loneliness and primary care usage $\mathrm{T} 0$ ).

\section{RESULTS}

\section{Does this SP pathway reduce healthcare usage?}

Table 2 presents the descriptive statistics and correlations for each $\mathrm{T} 0 / \mathrm{T} 1$ variable, and change in number of group memberships between $\mathrm{T} 0$ and $\mathrm{T} 1$.

Patients used primary care services less at T1 $(n=797)$ than T0 $(\mathrm{n}=1063)$, with a $25 \% \quad(\mathrm{n}=266)$ reduction in appointments. Participants' primary care use decreased significantly between T0 $(M=5.9, S D=8.2)$ and $\mathrm{T} 1(M=4.5$, $S D=8.4), F(1,176)=9.14, \mathrm{p}=0.003$.

\section{Does this SP pathway reduce healthcare use via SC processes?}

Participants' number of group memberships increased significantly between T0 $(M=1.89, S D=1.59)$ and T1 $(M=2.21, \quad S D=1.87, \quad F(1,177)=5.34, \quad \mathrm{p}=0.022, \quad$ partial $\eta 2=0.029$ ). Supporting predictions, we found a significant relationship between change in number of group memberships between $\mathrm{T} 0$ and $\mathrm{T} 1$ and primary healthcare usage T1 through community belonging $\mathrm{T} 1$ and loneliness T1, Effect $=-0.04$, Boot $S E=0.02$, Boot $L L C I=-0.09$, Boot $U L C I=-0.005$. Change in number of group memberships was a positive predictor of community belonging $\mathrm{T} 1$, Coeff $=0.09, S E=0.04, t=2.61, \mathrm{p}=0.01, L L C I=0.02, U L C I=0.16$, while community belonging $\mathrm{T} 1$ was a negative predictor of loneliness T1, Coeff $=-0.31, S E=0.07, t=-4.15, \mathrm{p}=0.0001$, $L L C I=-0.45$, $U L C I=-0.16$, which was a positive predictor of primary healthcare usage T1, Coeff $=1.41, S E=0.45$, $t=3.13, \mathrm{p}=0.002, L L C I=0.52, U L C I=2.31$. The total effect of change in number of group memberships on primary healthcare usage T1 was non-significant, Effect $=-0.07$, $S E=0.18, t=-0.39, \mathrm{p}=0.70, L L C I=-0.42, U L C I=0.28$ (it is appropriate to test for indirect effects when the total effect is non-significant; this is known as indirect-only mediation $^{58}$ ), and this remained almost unchanged when 
Table 2 T0/T1 ( $n=178)$ : descriptive statistics and intercorrelations for key variables

\begin{tabular}{|c|c|c|c|c|c|c|c|c|c|c|c|c|c|}
\hline Variable & 1 & 2 & 3 & 4 & 5 & 6 & 7 & 8 & 9 & 10 & 11 & 12 & 13 \\
\hline $\begin{array}{l}\text { 1. Change in No. of } \\
\text { groups } \\
\text { (TO-T1, } M=0.33 \text {, } \\
S D=2.15 \text { ) }\end{array}$ & - & & & & & & & & & & & & \\
\hline $\begin{array}{l}\text { 2. No. of groups T0 } \\
(1-10, M=1.89 \text {, } \\
S D=1.59)\end{array}$ & $-0.53^{\star \star \star}$ & - & & & & & & & & & & & \\
\hline $\begin{array}{l}\text { 4. Community } \\
\text { belonging T0 } \\
(1-4, M=2.72, S D=1.12)\end{array}$ & $-0.16^{\star}$ & $0.31^{\star \star \star}$ & 0.08 & - & & & & & & & & & \\
\hline $\begin{array}{l}\text { 7. Primary care use } T 1 \\
(M=4.48, S D=8.32)\end{array}$ & 0.01 & 0.01 & 0.01 & -0.06 & $-0.14 \dagger$ & $0.69^{\star \star \star}$ & - & & & & & & \\
\hline $\begin{array}{l}\text { 8. Loneliness T0 } \\
(1-5, M=2.42, S D=1.13 \text {, } \\
\alpha=0.88)\end{array}$ & 0.15 & $-0.20^{\star \star}$ & -0.001 & $-0.38^{\star \star *}$ & $-0.29^{\star \star \star}$ & 0.08 & $0.21^{\star *}$ & - & & & & & \\
\hline $\begin{array}{l}\text { 9. Loneliness T1 } \\
(1-5, M=2.35, S D=1.00 \text {, } \\
\alpha=0.87)\end{array}$ & 0.06 & $-0.15^{\star}$ & -0.06 & $-0.25^{\star \star}$ & $-0.40^{*}$ & $0.20^{\star \star}$ & $0.32^{\star \star \star}$ & $0.44^{\star \star \star}$ & - & & & & \\
\hline $\begin{array}{l}\text { 10. Age } \\
(M=55.75, S D=13.80)\end{array}$ & -0.09 & $0.19^{*}$ & 0.07 & $0.19^{\star}$ & 0.08 & -0.02 & -0.02 & $-0.26^{\star \star}$ & $-0.22^{\star \star}$ & - & & & \\
\hline
\end{tabular}

${ }^{* * *} \mathrm{p}<0.001 ;{ }^{* *} \mathrm{p}<0.01 ;{ }^{*} \mathrm{p}<0.05 ; \mathrm{\dagger p}<0.10$.

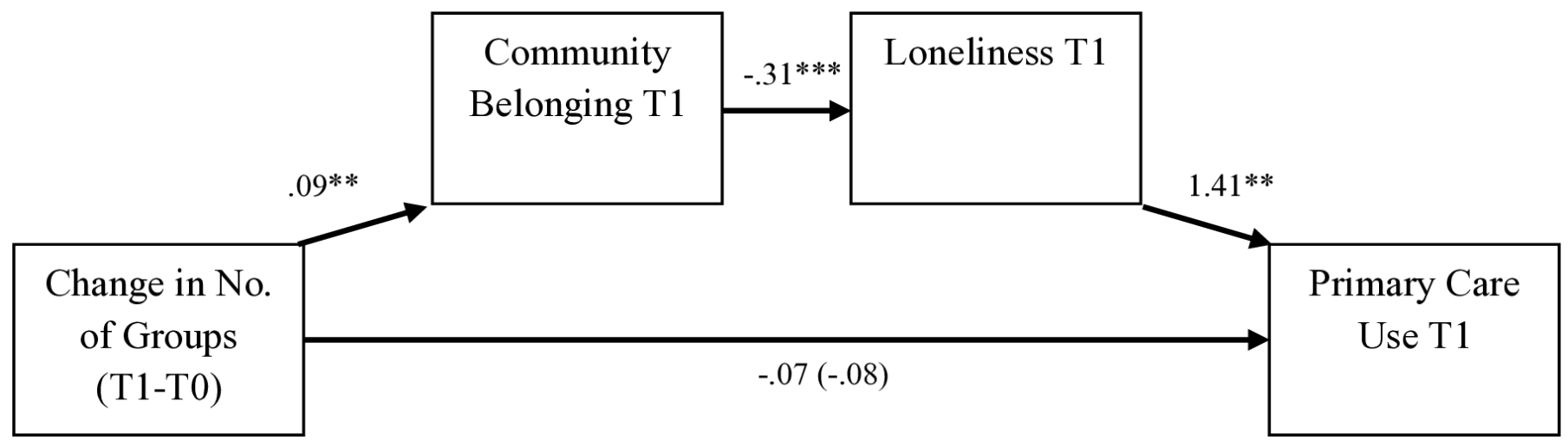

Figure 1 Model depicting the significant indirect effect of change in number of group memberships between T0 and T1 on primary healthcare usage T1 via community identification T1 and loneliness T1. Community identification T0, loneliness T0, primary healthcare usage T0, gender, age, relationship status, employment status, and education were controlled for in the analysis. Bracketed coefficient is the direct effect. Note: ${ }^{* \star *} \mathrm{p}<.001 ;{ }^{* \star} \mathrm{p} \leq .01$. 
community belonging $\mathrm{T} 1 /$ loneliness $\mathrm{T} 1$ were accounted for (direct effect), Effect $=-0.08, S E=0.18, t=-0.43, \mathrm{p}=0.68$, $L L C I=-0.43$, $U L C I=0.27$. See figure 1 for the model (to test the possibility that number of group memberships could predict loneliness without first predicting community belonging, we re-ran our PROCESS model with community belonging removed (ie, we used model 4, which only involves one mediator). The indirect effect of change in number of groups (T1-T0) on primary care use $\mathrm{T} 1$ via loneliness T1 was non-significant (Effect $=-003$, Boot $S E=0.05$, Boot LLCI $=-0.17$, Boot $U L C I=0.06)$ ).

\section{DISCUSSION}

As predicted, psychosocial factors were important for predicting reductions in primary care usage at 4 months following SP pathway participation. While we did not expect the full benefits of group membership on healthcare usage to be immediately apparent within this short implementation period (many previous SP evaluations have only reported benefits after 6 months, or even longer ${ }^{59}$ ), the fact that there were significant relationships between social psychological variables and service use is promising.

Our mediation analysis allows us to move beyond associative results to explore between-variable relations. From this, we can determine that possessing more group memberships predicts a stronger sense of community belonging, which in turn predicts lower levels of loneliness, which in turn predicts reduced primary care use. Crucially, the serial relationship through these mediators is significant and occurs independently of any relationships with age, gender, relationship status or educational background. We can assert that group memberships predict these patients' reduced service usage via community belonging and reductions in loneliness.

\section{GENERAL DISCUSSION}

As we have argued above and elsewhere (eg, previous works $^{40}{ }^{49}$ ), SP is a successful practice in need of a theoretical explanation. While there is abundant evidence that SP can (and does) work to redress the consequences of social isolation, the question of how and why it has its effects remains unanswered. Given the disparate variety of possible SP models, and the wide variation in effectiveness measures, ${ }^{41}$ it is crucial to use methodological triangulation and advanced analyses to identify 'active ingredients' which will highlight this complex intervention's benefits. ${ }^{60}$ Doing so will foster a common understanding of the purposes/functions of SP, which should improve communication, recruitment, engagement, service delivery and outcomes.

Our research constitutes a first step in this direction by exploring how this particular pathway is used, experienced and understood by different actors. Our qualitative analyses point to a consensus among GPs, SP staff and patients: loneliness and social isolation-key threats to patient health—can be addressed through SP.
In line with research in the social cure tradition which has demonstrated a direct link between lack of social group connectedness and GP attendance, ${ }^{12}$ the absence of meaningful associative relationships is recognised by these health professionals to have detrimental health effects. Moreover, social isolation was perceived by GPs as being directly related to the frequency of inappropriate usage of primary care services by some patients and SP was recognised as a remedy for this.

Analysis of patient perspectives shows that these social factors were pivotal to their positive experience of the pathway. The supportive and encouraging role played by HCs/LWs, welcoming attitudes, acceptance from activity groups and the more global sense of being connected to their community were crucial prerequisites for any pathway benefits. In line with the social cure approach, ${ }^{61}$ the psychological and social resources flowing from rich group-based social connections were experienced as the root of SP's positive effects.

Our patient survey allowed us to empirically examine these associations. Our results replicated previous findings showing the importance of group memberships for health service usage (eg, Cruwys et $a l^{2}$ ), and we illustrate the predictive direction of this effect, with group memberships predicting increased community belonging, which predicts reduced loneliness. Moreover, these factors serially predict health service use, even when controlling for age, gender, relationship status and education. In effect, our results validate the perceptions of healthcare staff and the experiences of patients in evidencing the role of $\mathrm{SC}$ processes in this SP pathway.

Of course, there are limitations to our research. We acknowledge that the results from our longitudinal analyses are based on a short time period and are likely to strengthen over longer time periods, ${ }^{49}$ although observing benefits after such a short time is promising. Furthermore, the specific characteristics of this sample (adults with complex health needs from across the socioeconomic spectrum) need to be borne in mind when considering the applicability of SP to other populations. The pathway's geographical area is a relatively affluent suburban borough of East Midlands that experiences much lower levels of crime/deprivation than nearby urban areas. The effectiveness of SP in areas with fewer community resources/ lower community cohesion remains to be determined. We predict that within deprived communities/disadvantaged social groups, the benefits of social connections are likely to be more pronounced, while the opportunities to establish them are more limited. Importantly, the designated GP advocates of the SP and the location of some of the LCs/ HWs within these GP practices, facilitated referrals, visibility and engagement with the pathway.

Bearing in mind these limitations, our work, among the first to quantify the effects of SP, has several specific implications arising from the applicability of the social cure perspective. The first pertains to the determination of what elements of SP could have most effect, and through which processes. We predict that SP initiatives which reconnect isolated patients with their local community, should help 
unlock community-based sources of social/emotional support, thereby enabling them to better cope with loneliness. Conversely, those pathways which deliver one-to-one treatment without recognition of patients' social needs may fail to unlock these support sources. The Social Cure literature offers a manualised five-session psychological intervention (Groups4Health) aimed at developing and maintaining social group membership, which has been shown to tackle loneliness by building participants' sense of group belonging ${ }^{62}$ as well as a psychometrically valid 'Social Identity Mapping' tool that can be used to produce a visual representation of an individual's group memberships. ${ }^{63}$ Either could be integrated into future SP initiatives and provide a strong basis for identifying and meaningfully addressing gaps in social connection. Identification of these gaps and individual needs can help avoid mismatching and increase connection with the activity groups.

The second recommendation comes from an appreciation of the role of community belonging in reducing loneliness. While initiatives such as SP are often geared towards using community groups/resources, they rarely consider local communities themselves as a source of wellbeing. This is at odds with increasing evidence attesting to the social and psychological impacts of neighbourhoods on health, well-being and resilience. ${ }^{64-66}$ The SC model predicts that greater sense of community identification and belonging can unlock a wide range of psychological, social and practical supports, including increased trust, reciprocal helping and collective enterprise. Our work suggests that SP initiatives which focus on the locatedness of their patients within their local communities, and which serve to enhance this sense of connectedness/ belonging among the broader population will reach more individuals, create more sustainable community environments and be a more effective (and 'social') cure.

Twitter Blerina Kellezi @Blerina_Kellezi, Juliet Ruth Helen Wakefield @drjwakefield, Clifford Stevenson @DrCliffordSteve, Niamh McNamara @DrNiamhMcNamara,

Elizabeth Mair @ElizabethMair_, Mhairi Bowe @MhairiBowe, lain Wilson @Dr_lain_ Wilson and Moon Moon Halder @moonhalder

Acknowledgements The research team would like to thank Rushcliffe Borough Council, Let's Live Well in Rushcliffe and the community co-production team with their involvement in this research. Name of guarantor: BK, JRHW, CS, NM, MB and IW accept full responsibility for the work and/or the conduct of the study, had access to the data and controlled the decision to publish.

Contributors BK: designed, conducted the research, analysed the data and drafted and revision of this paper. JHRW: designed, conducted the research, analysed the data, and co-drafted and revised this paper. CS: obtained the funding, designed, conducted the research and contributed to the drafting and revision of this paper. NM: designed, conducted the research, analysed the data and contributed to the drafting and revision of this paper.MB: designed, conducted the research and contributed to the drafting and revision of this paper. EM: designed, conducted the research, analysed the data and contributed to the drafting of this paper. IW: designed, conducted the research and contributed to the drafting of this paper. $\mathrm{MH}$ : conducted the research and contributed to the drafting of this paper.

Funding This research was funded by ImROC (Implementing Recovery Through Organisational Change). ImROC played no role in the design of the study, the analysis/interpretation of the data, the writing of the paper or the decision to submit this article to BMJ, but ImROC employees gathered the Study 2 data. Sponsor: The study was sponsored by Nottingham Trent University and the sponsor reviewed and approved all study documents. Statement of independence: The researchers conducted the research independently from funders.
Competing interests None declared.

Patient consent for publication Not required.

Provenance and peer review Not commissioned; externally peer reviewed.

Data availability statement Data are available on reasonable request. No data are available.

Open access This is an open access article distributed in accordance with the Creative Commons Attribution Non Commercial (CC BY-NC 4.0) license, which permits others to distribute, remix, adapt, build upon this work non-commercially, and license their derivative works on different terms, provided the original work is properly cited, appropriate credit is given, any changes made indicated, and the use is non-commercial. See: http://creativecommons.org/licenses/by-nc/4.0/.

\section{ORCID iDs}

Blerina Kellezi http://orcid.org/0000-0003-4825-3624

Juliet Ruth Helen Wakefield https://orcid.org/0000-0001-9155-9683

Clifford Stevenson https://orcid.org/0000-0002-2438-6425

Niamh McNamara https://orcid.org/0000-0003-3123-3678

Elizabeth Mair https://orcid.org/0000-0001-5356-5927

Mhairi Bowe https://orcid.org/0000-0002-0491-1472

lain Wilson https://orcid.org/0000-0001-6670-9328

Moon Moon Halder https://orcid.org/0000-0002-1608-6027

\section{REFERENCES}

1 England NHS. Nhs England news: 1.4 million people referred to NHS mental health therapy in the past year, 2017. Available: https://www. england.nhs.uk/2017/12/1-4-million-people-referred-to-nhs-mentalhealth-therapy-in-the-past-year/ [Accessed 1 Dec 2018].

2 UK Medicines Information. Operational productivity and performance in English NHS acute hospitals: unwarranted variations, 2016. Available: https://www.gov.uk/government/uploads/system/uploads/ attachment_data/file/499229/Operational_productivity_A.pdf [Accessed 12 Dec 2018].

3 Holt-Lunstad J, Smith TB, Baker M, et al. Loneliness and social isolation as risk factors for mortality: a meta-analytic review. Perspect Psychol Sci 2015;10:227-37.

4 Mistry R, Rosansky J, McGuire J, et al. Social isolation predicts rehospitalization in a group of older American veterans enrolled in the upbeat program. Int J Geriatr Psychiatry 2001;16:950-9.

5 Haslam C, Cruwys T, Haslam SA. "The we's have it": Evidence for the distinctive benefits of group engagement in enhancing cognitive health in aging. Soc Sci Med 2014;120:57-66.

6 Olaya B, Domènech-Abella J, Moneta MV, et al. All-Cause mortality and multimorbidity in older adults: the role of social support and Ioneliness. Exp Gerontol 2017;99:120-6.

7 Shankar A, McMunn A, Demakakos P, et al. Social isolation and loneliness: prospective associations with functional status in older adults. Health Psychology 2017;36:179-87.

8 Santini ZI, Fiori KL, Feeney J, et al. Social relationships, Ioneliness, and mental health among older men and women in Ireland: a prospective community-based study. J Affect Disord 2016;204:59-69.

9 Luo Y, Hawkley LC, Waite LJ, et al. Loneliness, health, and mortality in old age: a national longitudinal study. Soc Sci Med 2012;74:907-14.

10 Dreyer K, Steventon A, Fisher R, et al. The association between living alone and health care utilisation in older adults: a retrospective cohort study of electronic health records from a London general practice. BMC Geriatr 2018;18:269.

11 Gerst-Emerson K, Jayawardhana J. Loneliness as a public health issue: the impact of loneliness on health care utilization among older adults. Am J Public Health 2015;105:1013-9.

12 Cruwys T, Wakefield JRH, Sani F, et al. Social isolation predicts frequent attendance in primary care. Ann Behav Med 2018;52:817-29.

13 Moth G, Olesen F, Vedsted P. Reasons for encounter and disease patterns in Danish primary care: changes over 16 years. Scand $J$ Prim Health Care 2012;30:70-5.

14 Prins MA, Verhaak PFM, van der Meer K, et al. Primary care patients with anxiety and depression: need for care from the patient's perspective. J Affect Disord 2009;119:163-71.

15 Bebbington PE, Meltzer H, Brugha TS, et al. Unequal access and unmet need: neurotic disorders and the use of primary care services. Psychol Med 2000;30:1359-67.

16 Corrigan JM, Donaldson MS, Kohn LT. Crossing the quality chasm: a new health system for the 21st century. Washington, DC: National Academy Press, 2001. 
17 The King's Fund (2017). Public attitudes and expectations: future trends, 2017. Available: https://www.kingsfund.org.uk/projects/timethink-differently/trends-public-attitudes-expectations [Accessed 11 Dec 2018].

18 World Health Organization. The world health report 2001: mental health new understanding, new hope. World Health Organization, 2001.

19 Cacioppo JT, Cacioppo S. Social relationships and health: the toxic effects of perceived social isolation. Soc Personal Psychol Compass 2014;8:58-72.

20 Knapp M, Bauer A, Perkins M, et al. Building community capital in social care: is there an economic case? Community Dev $J$ 2013;48:313-31.

21 Steptoe A, Shankar A, Demakakos P, et al. Social isolation, loneliness, and all-cause mortality in older men and women. Proc Natl Acad Sci U S A 2013;110:5797-801.

22 WHO. Patient engagement: technical series on safer primary care. Geneva: World Health Organization, 2016.

23 Chitnis A, Dowrick C, Byng R, et al. Guidance for health professionals on medically unexplained symptoms, 2014. Available: www.rcgp.org.uk/clinical-and-research/our-programmes/ / /media/ Files/CIRC/Mental\%20Health\%20 -\%202014/4\%20Medically\% 20Unexplained\%20Symptoms\%20\%20guidance\%202014.ashx [Accessed 13 March 2019].

24 Howie JG, Heaney DJ, Maxwell M, et al. Quality at general practice consultations: cross sectional survey. BMJ 1999;319:738-43.

25 Sambrook Smith M, Lawrence V, Sadler E, et al. Barriers to accessing mental health services for women with perinatal mental illness: systematic review and meta-synthesis of qualitative studies in the UK. BMJ Open 2019;9:e024803.

26 South J, Higgins TJ, Woodall J, et al. Can social prescribing provide the missing link? Prim Health Care Res Dev 2008;9:310-8.

27 Bertotti M, Frostick C. The social prescribing service in London borough of Waltham forest final evaluation report. University of East London: Institute of Health and Human Development, 2017.

28 Liles A, Darnton P. Social prescribing in Wesses: understanding its impact and supporting spread, 2017. Available: http://wessexahsn. org.uk/img/projects/Wessex\%20Social\%20Prescribing-1529938576. pdf [Accessed 16 Oct 2018]

29 HSE. Donegal social prescribing for health and wellbeing. evaluation report April 2015, 2015. Available: http://docs.wixstatic.com/ugd/ b6d55d_7de160a4d6954491b04ce123c8e37237.pdf [Accessed 16 Oct 2018].

30 Longwill A. Independent evaluation of Hackney well family service, 2014. Available: https://www.family-action.org.uk/content/uploads/ 2014/07/Wellfamily-Evaluation-Summary.pdf [Accessed 22 Feb 2019]

31 Palmer D, Wheeler J, Hendrix E, et al. Social prescribing in Bexley: pilot evaluation report, 2017. Available: http://mindinbexley.org.uk/ wp/wp-content/uploads/2017/06/Social-Prescribing-in-Bexley-PilotEvaluation-Report.pdf [Accessed 22 Feb 2019].

32 Potter S. Arts on prescription 2010-12 research report, 2013. Available: http://www.artsandminds.org.uk/wp-content/uploads/ 2015/10/arts-on-prescription-2010_12_research-report_susan-potter. pdf [Accessed 5 Jan 2019].

33 Cattan M, White $\mathrm{M}$, Bond J, et al. Preventing social isolation and loneliness among older people: a systematic review of health promotion interventions. Ageing Soc 2005;25:41-67.

34 Dickens AP, Richards SH, Hawton A, et al. An evaluation of the effectiveness of a community mentoring service for socially isolated older people: a controlled trial. BMC Public Health 2011;11:218.

35 Hemingway A, Jack E. Reducing social isolation and promoting well being in older people. Qual Ageing Older Adults 2013;14:25-35.

36 Kimberlee R. Gloucestershire clinical commissioning group socia prescribing service: evaluation report, 2016. Available: http://eprints. uwe.ac.uk/30293/3/Report\%25406.pdf [Accessed 5 Jan 2019].

37 Dayson C, Bashir N. The social and economic impact of the Rotherham social prescribing pilot: main evaluation report. Sheffield Hallam university: centre for regional economic and social research (CRESR), 2014. Available: http://shura.shu.ac.uk/18961/1/DaysonSocialAndEconomiclmpact-Rotherham\%28VoR\%29.pdf [Accessed 6 January 2019].

38 Envoy Partnership. Self-Care Social Prescribing: Kensington \& Chelsea Social Council and NHS West London Clinical Commissioning Group, Social Return on Investment, 2018. Available: https://www.kcsc.org.uk/sites/kcsc.org.uk/civi_files/files/civicrm/ persist/contribute/files/Self\%20Care/7641 SROI-Report DIGITAL AW.pdf [Accessed 5 Sep 2018].

39 Cawston P. Social prescribing in very deprived areas. $\mathrm{Br} J$ Gen Pract $2011 ; 61$.
40 Stevenson C, Wilson I, Mcnamara N, et al. Social prescribing: a practice in need of a theory, 2019. Br J Gen Prac. Available: https:// bjgp.org/content/social-prescribing-practice-need-theory

41 Husk K, Elston J, Gradinger F, et al. Social prescribing: where is the evidence? Br J Gen Pract 2019;69:6-7.

42 Popay J, Kowarzik U, Mallinson S, et al. Social problems, primary care and pathways to help and support: addressing health inequalities at the individual level. Part I: the GP perspective. Journal of Epidemiology \& Community Health 2007;61:966-71.

43 Stickley T, Hui A. Social prescribing through arts on prescription in a U.K. City: referrers' perspectives (Part 2). Public Health 2012;126:580-6.

44 Haslam C, Jetten J, Alexander SH. The social cure: identity, health and well-being. Psychology Press: Hove, 2012

45 Haslam C, Jetten J, Cruwys T, et al. The new psychology of health. unlocking the social cure. London: Routledge, 2018.

46 Sani F, Madhok V, Norbury M, et al. Greater number of group identifications is associated with healthier behaviour: evidence from a Scottish community sample. Br J Health Psychol 2015;20:466-81.

47 Greenaway KH, Haslam SA, Cruwys T, et al. From "we" to "me": Group identification enhances perceived personal control with consequences for health and well-being. J Pers Soc Psychol 2015;109:53-74.

48 Haslam SA, O'Brien A, Jetten J, et al. Taking the strain: social identity, social support, and the experience of stress. Br J Soc Psychol 2005;44:355-70.

49 Halder MM, Wakefield JR, Bowe M, et al. Evaluation and exploration of a social prescribing initiative: study protocol. J Health Psychol 2018:1359105318814160.

50 Braun V, Clarke V. Using thematic analysis in psychology. Qual Res Psychol 2006;3:77-101.

51 Braun V, Clarke V. Successful qualitative research: a practical guide for beginners. London: Sage, 2013.

52 Irving G, Neves AL, Dambha-Miller $\mathrm{H}$, et al. International variations in primary care physician consultation time: a systematic review of 67 countries. BMJ Open 2017;7:e017902.

53 Erdfelder E, Faul F, Buchner A. GPOWER: a general power analysis program. Behavior Research Methods, Instruments, \& Computers 1996;28:1-11.

54 Hayward K, Dowds L, Shaw C. Belonging and alienation in the new Northern Ireland; 2014.

55 Hays RD, DiMatteo MR. A short-form measure of loneliness. J Pers Assess 1987;51:69-81.

56 Kellezi B, Baines DL, Coupland C, et al. The impact of injuries on health service resource use and costs in primary and secondary care in the English NHS. J Public Health 2016;38:e464-71.

57 Zhao X, Lynch JG, Chen Q, et al. Reconsidering Baron and Kenny: myths and truths about mediation analysis. J Consum Res 2010;37:197-206.

58 Hayes AF. Introduction to mediation, moderation, and conditional process analysis: a regression-based approach. London: Guilford Publications, 2017

59 Kimberlee R. Gloucestershire clinical commissioning group social prescribing service: evaluation report, 2016. Available: http://eprints. uwe.ac.uk/30293/3/Report\%25406.pdf [Accessed 19 Jan 2019].

60 Medical Research Council (2019). Developing and evaluating complex interventions: new guidance, 2019. Available: http://www. mrc.ac.uk/Utilities/Documentrecord/index.htm?d=MRC004871 [Accessed 19 Jan 2019].

61 Jetten J, Haslam SA, Cruwys T, et al. Advancing the social identity approach to health and well-being: progressing the social cure research agenda. Eur J Soc Psychol 2017;47:789-802.

62 Haslam C, Cruwys T, Chang MX-L, et al. Groups 4 health reduces loneliness and social anxiety in adults with psychological distress: findings from a randomized controlled trial. J Consult Clin Psychol 2019;87:787-801.

63 Cruwys T, Steffens NK, Haslam SA, et al. Social identity mapping: a procedure for visual representation and assessment of subjective multiple group memberships. Br. J. Soc. Psychol. 2016;55:613-42.

64 McNamara N, Stevenson C, Muldoon OT. Community identity as resource and context: a mixed method investigation of coping and collective action in a disadvantaged community. Eur J Soc Psychol 2013;43:393-403.

65 Fong P, Cruwys T, Haslam C, et al. Neighbourhood identification and mental health: how social identification moderates the relationship between socioeconomic disadvantage and health. J Environ Psychol 2019;61:101-14.

66 Drury J. The role of social identity processes in mass emergency behaviour: an integrative review. Eur Rev Soc Psychol 2018;29:38-81. 